\title{
Damages in adjacent structures due to foundation excavation
}

\author{
Turgay Cosgun
}

\author{
Baris Sayin
}

\begin{abstract}
Unplanned urbanization and socio-economic changes cause to environmental issues due to the rapid increase in modern technology and industrialization. This situation can lead to significant environmental problems in large cities. During new constructions in limited areas or renewal of existing structures, severe damages, and even collapse issues in adjacent buildings can arise due to the fundamental excavation performed in violation of science and craft rules. The study focuses on reasons of damages occurred in adjacent structures due to foundation excavation.
\end{abstract}

Keywords - Foundation excavation, structural damage, partial collapse, Inclinometer

\section{Introduction}

In metropolitan areas around the world, infrastructure construction and renovation projects often require deep excavations. The prospect of deep excavations being close to existing structures is almost a certainty. In light of this reality, the importance of predicting and minimizing the resulting excavation-related building damage is of major concern to contractors, owners, and the public. A concise yet reliable method is required to approximate damage [1]. As a result of the increase in the population, new construction works performed especially in big city to meet the demand for new housing lead to emergency of many issues. During construction work, due to the foundation excavations carried out without taking into account the interaction with the surrounding structures, structural damages and even collapses can occur in adjacent structures [2-9].

In modern urban environments, heavy construction often should be conducted immediately adjacent to neighboring properties and structures.

Turgay Cosgun

Department of Civil Engineering / Istanbul University Turkey

Baris Sayin

Department of Civil Engineering / Istanbul University Turkey

Cemil Akcay

Department of Civil Engineering / Istanbul University

Turkey

Baris Yildizlar

Department of Civil Engineering / Istanbul University Turkey

\author{
Cemil Akcay
}

Baris Yildizlar

Often the neighboring buildings are occupied and must remain open to business or residency during the full course of construction. This can be problematic if the new construction involves high levels of noise or vibration (i.e., pile-driving or heavy traffic loads), deep excavation, or dewatering [10].

Damage to buildings adjacent to excavations can be a major design consideration when constructing facilities in congested urban areas. As new buildings are constructed, the excavations required for basements affect nearby existing buildings, especially those founded on shallow foundations [11]. Excavation of underground facilities and deep building foundations in urban areas must be controlled to limit potentially damaging ground settlements to adjacent structures. Buildings on shallow foundations, which are often historic masonry and low-rise frame structures, are of particular concern [12].

A major concern for projects involving deep excavations in urban areas is the impact of excavation-related ground movements on adjacent buildings and utilities. These impacts specifically refer to the translation and rotation of the structure in reaction to lateral ground movements and surface settlement. These translations and rotations result in direct tensile strains, bending strains, and shear strains in the structural and nonstructural members of the buildings. A purely theoretical approach to estimating building response to excavation related deformations is not possible due to the variability of the many factors that contribute to the response. Consequently, building response is estimated and evaluated on the basis of empirical observations and simplified structural approximations. The goal of estimating and evaluating building response is to provide limiting criteria that will safeguard the structure against unacceptable damage [13].

A major concern during the planning and execution of underground construction is the impact of construction related ground movements on adjacent buildings and utilities. During excavation and support of tunnels and open cuts, changes in the state of stress in the ground mass around the excavation and loss of ground occur. These changes in stress and ground losses are typically expressed in the form of vertical and horizontal ground movements. The ground movements, in turn, cause any structures supported by the affected ground to translate, rotate, deform, distort, and possibly sustain damage. As a consequence, important tasks facing both the engineer and the contractor are the estimation of the magnitude and distribution of the ground movements to be caused by the construction procedures and the tolerance of the structures and utilities to the deformations and distortions sustained as a result of the ground displacements [14]. 
Proc. of the Fourth International Conference on Advances in Civil, Structural and Environmental Engineering - ACSEE 2016. Copyright $(\odot$ Institute of Research Engineers and Doctors. All rights reserved.

ISBN: 978-1-63248-114-6 doi: 10.15224/ 978-1-63248-114-6-28

During the construction of engineering structures, inclinometer measurements are used extensively in order to monitoring and detection deformations and slope movements occurred in the construction area. All horizontal movements in the ground movements using inclinometer measurements can be determined. Furthermore, soil movements in the construction of main dam and pile foundation system are measured by installing inclinometer pipes [15].

In this study, damages in adjacent structures and soil movements are examined as observational and field studies due to foundation excavation performed for building construction. In the scope of the examined area, it is stated that parameters to be considered during foundation excavations.

\section{The Case Study}

\section{A. The Examined Area}

The examined structure is located in Bahcelievler, Istanbul, Turkey (Fig. 1). In the construction process, shoring system with prestressed anchor RC bored pile is Scheduled around foundation pit excavation [16]. Using the shoring- and foundation-plans, inclinometer measurements, observational examinations, it is determined that soil characteristics of the area where shoring system and the reinforced concrete structure are built. However, before the construction, soil investigations in outside the construction area are not performed. Shoring system to support the foundation pit excavation is specified considering soil investigation report.

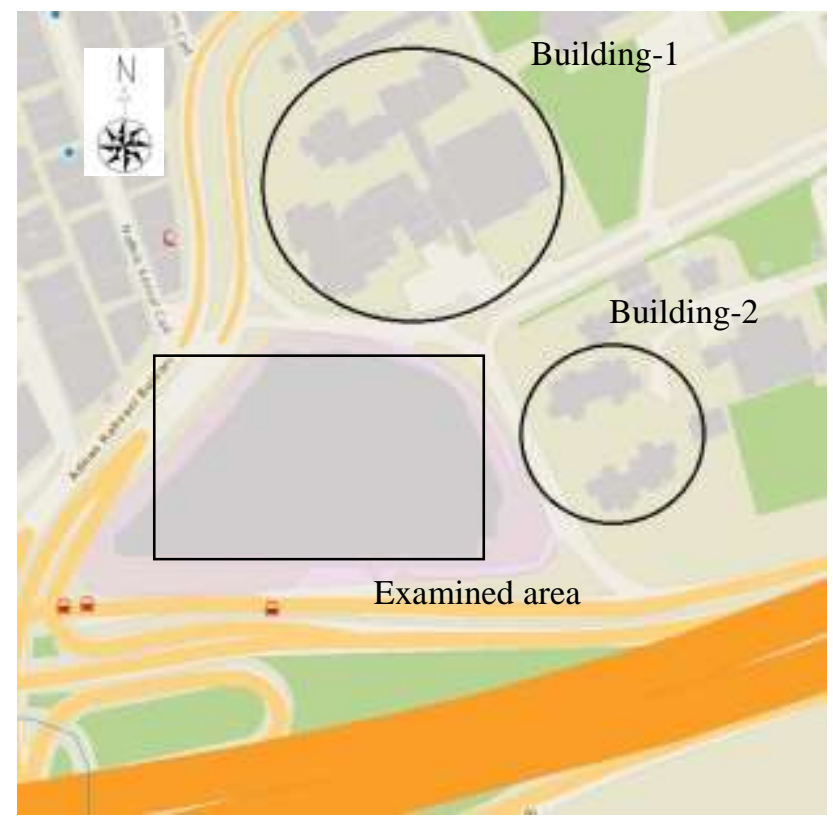

Figure 1. The locations of the examined area and two damaged structures

TS498, TS500 and TEC 2007 regulations are based on the design process of the building [17-19]. Also, the prepared project is in accordance with geotechnical soil investigation reports [20-21] and constructive rules. In addition to this, during implementation of the project, soil movements are measured placing inclinometers at specific points

\section{B. The Damaged Structures}

During the excavation works of the examined building construction, damage and cracks are occurred in load-bearing members and walls of hospital (Building-1) and public building (Building-2) (Fig. 1) [22].

\section{1) The damage evaluation of Building-1}

Technical examinations are carried out in the common areas and blocks $\mathrm{A} / \mathrm{B}$ of Hospital structure (Building-1), one of the damaged structures. In the observations and investigations in Block A, (i) Soil movements and collapses are occurred in garden area, and the roads around the structure (Fig. 2), (ii) Tension cracks and separations are occurred in boundary walls in the direction of foundation excavation direction (Fig. 3), (iii) Especially in the south facade overlooking the deep excavation, it is observed that separations in RC members and connections including rotations as a result of torsional effects due to sliding and subsidence of the ground (Fig. 4). The left part of the building block A is heavily subjected to, damaged deviating from the plumb line, so its stability and carrying capacity. have completely run out. Structural damage is not determined in the basement floor on the right side of the main entrance. The members subjected to damage is not observed in pool area of the third unit which has partially basement floor. In the observational examination of building block B is $220 \mathrm{~m}$ of the distance from the excavation site, especially in the wet areas of without basement unit on the left side of the main entrance, 45 degree angled tension cracks are appeared on walls depending on ground subsidence. Accordingly, micro cracks are occurred in wall-beam connections [22].

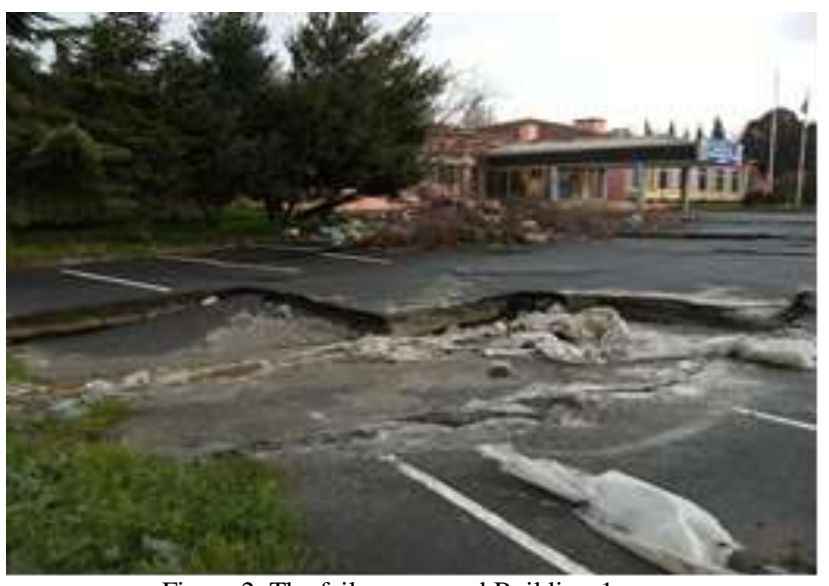

Figure 2. The failures around Building-1 
Proc. of the Fourth International Conference on Advances in Civil, Structural and Environmental Engineering - ACSEE 2016. Copyright $(\odot$ Institute of Research Engineers and Doctors. All rights reserved.

ISBN: 978-1-63248-114-6 doi: 10.15224/ 978-1-63248-114-6-28

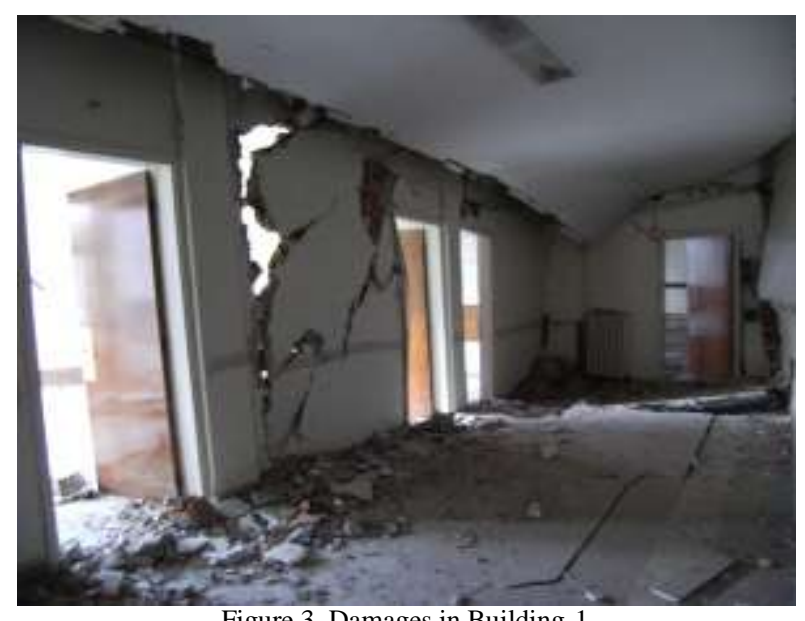

Figure 3. Damages in Building-1

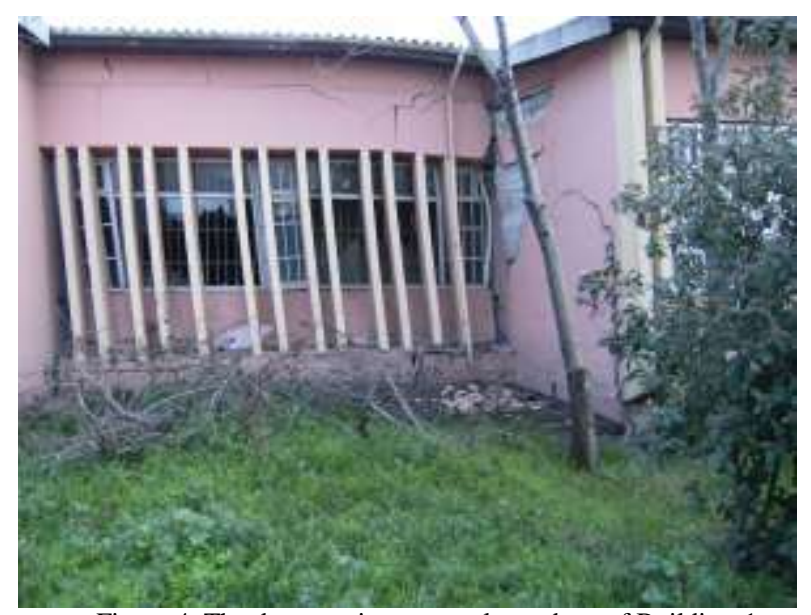

Figure 4. The damages in structural members of Building-1

\section{2) The damage evaluation of Building-2}

The damaged other structure, two-storey RC framed and Building-2, is seperated with a dilatation and consists of adjacent two groups of two blocks. In observations in the structure, (i) Soil movements and collapses are occurred in garden area, and the roads around the structure, (ii) Tension cracks and separations are occurred in boundary walls in the direction of foundation excavation direction, (iii) In the group I including Blocks 1 and 2, it is observed that cracks in connections of RC members and infilled walls, and 45 degree angled tension cracks in column-beam connections, (iv) It is determined to deviate from the plumb line the Block 2 of building group I (Fig. 5-8) [22].

The structure, Blocks 1 and 2 in building group I, couldn't use and repair due to separates in dilatation joints, collepses in garden and the mentioned issues. Therefore, it is necessary to destroye and rebuild of the building.

The structure, Blocks 3 and 4 in building group II, consists of horizontal- and vertical-cracks in column-wall and beamwall connections. Moreover, failures and deformations are specified in sidewalk of around the structure. In garden floor, it is observed that deformations similar to the structure, group I. Hereby, it is reached the conclusion that destroye and rebuild of the building.

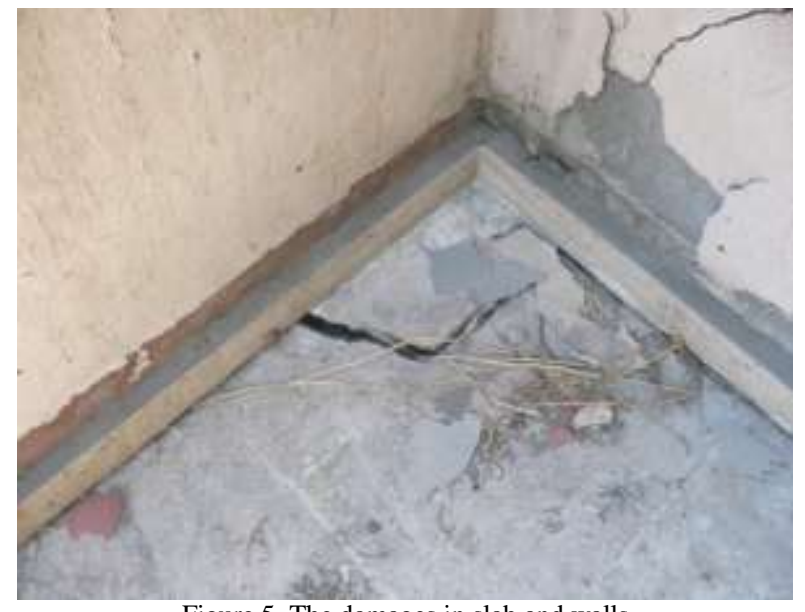

Figure 5. The damages in slab and walls

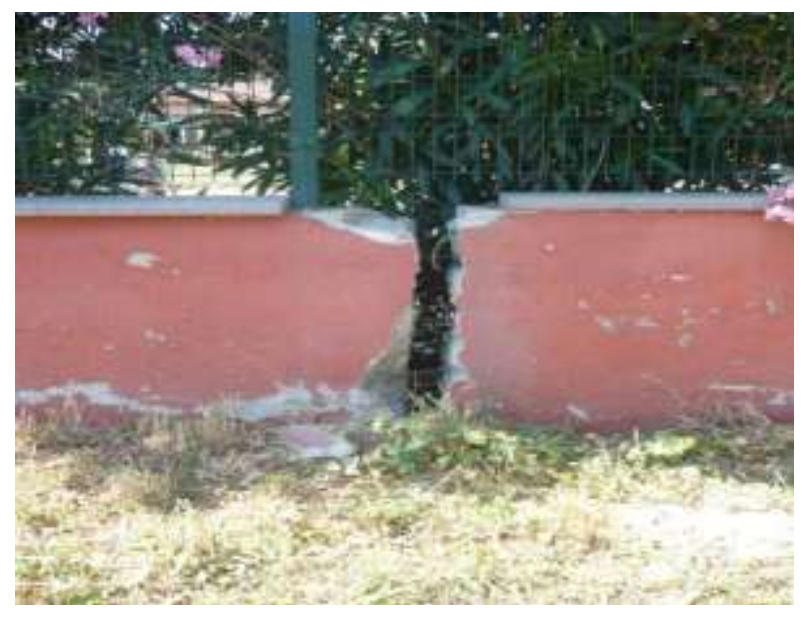

Figure 6. Seperations in walls due to soil movements

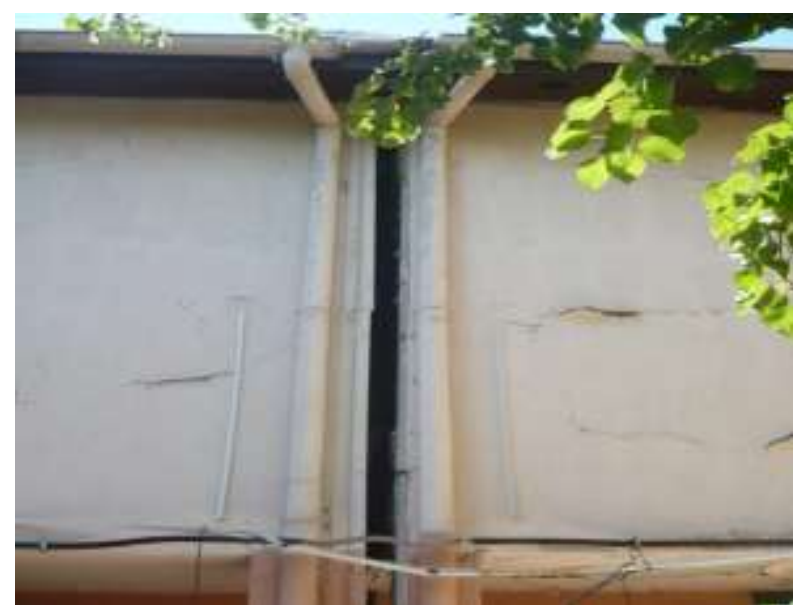

Figure 7. The separation in dilatation joints 
Proc. of the Fourth International Conference on Advances in Civil, Structural and Environmental Engineering - ACSEE 2016. Copyright $(\odot$ Institute of Research Engineers and Doctors. All rights reserved.

ISBN: 978-1-63248-114-6 doi: 10.15224/ 978-1-63248-114-6-28

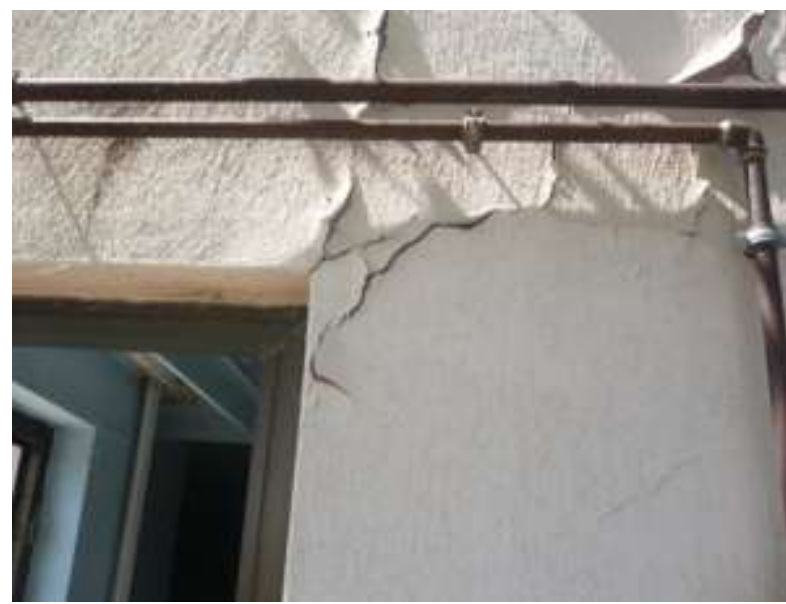

Figure 8 . The cracks in column-beam connections

In selected three inclinometer wells around the examined area, measurements are performed on twelve different dates different dates. Thus, it is determined that lateral movements, deformations in different depths of the ground. The selected well locations for inclinometer measurements are shown in Fig. 9.

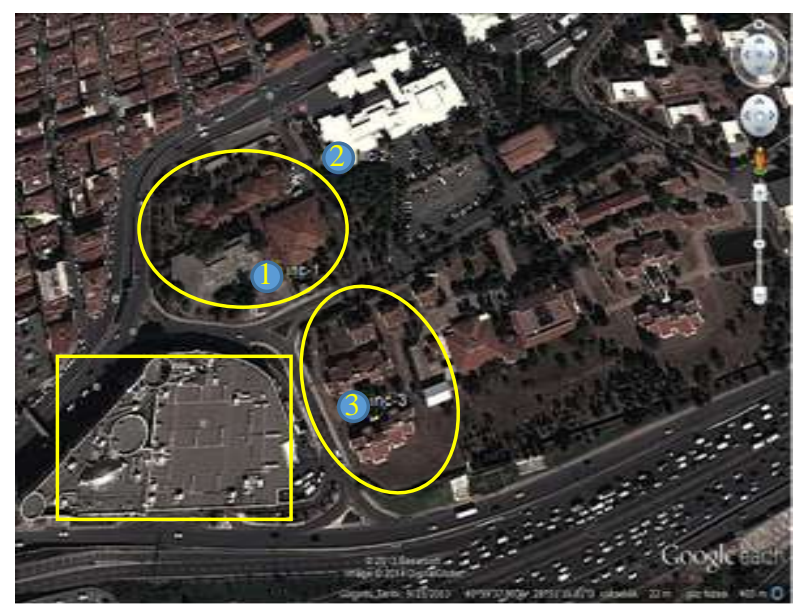

Figure 9. The locations of inclinometer well

In inclinometer measurements, A- and B-axes mean dominant slope direction -the expected direction of movement- and the direction perpendicular to it, respectively. Measurement data is given in Table 1 in the two axes.

TABLE I. INCLINOMETER MEASUREMENTS

\begin{tabular}{|c|c|c|}
\hline \multirow{2}{*}{ Inclinometer no } & \multicolumn{2}{|c|}{$\begin{array}{c}\text { Maximum displacement } \\
\text { on soil surface (mm) }\end{array}$} \\
\cline { 2 - 3 } & Axis- $\boldsymbol{A}$ & Axis-B \\
\hline 1 & 11.30 & 0.35 \\
\hline 2 & 7.70 & 21.35 \\
\hline 3 & 1.05 & 3.05 \\
\hline
\end{tabular}

In the inclinometer no. 1, a uniform movement is not observed in A- and B-axes in the measurements taken on different dates. After the date reading the maximum value, the stability achieved and ended up soil movement in this direction for the inclinometer no. 2. Although there is not a regular movement in the A-axis, the last reading in surface is measured as $3.05 \mathrm{~mm}$ for $\mathrm{B}$-axis in the inclinometer no. 3 . Considering time intervals of measurements, movements to cause excessive displacement, and sliding planes to occur as a result of these movements are not observed in the performed measurements in inclinometer wells. Generally, it can be stated that ground stability is maintained in the measurement locations

\section{Conclusions}

In the present study, the damages caused adjacent foundation excavation is examined based on damaged two structures. Before the foundation excavation is not considered ground conditions of both the area and adjacent plot. In soil, landslide and slope is occurred due to deep foundation excavation performed at the site without sufficient taking precaution. The results are obtained by inclinometer measurements and observational survey.

Ground movements and deformations are occurred in the foundation excavation and shoring work, these results in affected Building-1 and Building-2 located in the plot. In adjacent plots, the water in saturated ground is drained to the foundation excavation area. It is decreased that pore water pressure of soil in the plot that located examination of the examined structures. For this reason, ground subsidences appeared in the area of the structures.

Eventually, the causes of damages in two structures consist of: (i) the water-saturated ground to make the descent of rain water and presumptive waste water, (ii) Ground subsidence and deformations in foundation soil decreasing of pore water pressure of soil due to foundation excavation. In order to ensure normal use of the near buildings under the influence of foundation excavation, it is required that an accurate assessment on the influence of the excavating on the adjacent buildings damage. In addition to the issues mentioned, although detailed examinations are performed thorough investigation of inhomogeneous soils in large areas, the problems may occur due to the ground conditions in shoring systems, especially, in high-rise buildings.

\section{References}

[1] M. Kotheimer, and L. Bryson, "Damage approximation method for excavation-induced damage to adjacent buildings," Contemporary Topics in Ground Modification, Problem Soils, and Geo-Support: 65-72, 2009.

[2] R. Brent, and P. E. Leisenring, "Damage to adjacent building during construction - Expert investigation," The Experts, Robson Forensic, 2012.

[3] S. Boone "Ground-movement-related building damage," J. Geotech. Eng., 886-896, 1996.

[4] W. Wang, and Z. Xu, "Simplified analysis method for evaluating excavation-induced damage of adjacent buildings," Chinese J Geotech. Eng., 2010-S1.

[5] M. D. Boscardin E.J. Cording, and T. D. O'Rourke, "Case studies of building behavior in response to adjacent excavation," National Technical Information Service, 1978.

[6] T. D. O'Rourke, E. J. Cording, and M. Boscardin, "The ground movements related to braced excavation and their influence on adjacent buildings," National Technical Information Service, 1976.

[7] Y. Bian, and H. Huang, "Risk assessment of building damage induced by deep excavation," Chinese J Geotech. Eng., 2006-S1 
Proc. of the Fourth International Conference on Advances in Civil, Structural and Environmental Engineering - ACSEE 2016. Copyright $(\odot$ Institute of Research Engineers and Doctors. All rights reserved.

ISBN: 978-1-63248-114-6 doi: 10.15224/ 978-1-63248-114-6-28

[8] Y. Liu, and X. Wang, "Overview of the assessment on the damage from underground excavating on adjacent buildings," Chinese J Underground Space and Engineering, 2009-04

[9] D. Laefer, S. Ceribasi, J. Long, and E. Cording, "Predicting RC frame response to excavation-induced settlement,"J. Geotech. Geoenviron. Eng., 1605-1619, 2009.

[10] Damage from adjacent construction, http://www.exponent.com/ (Accessed on September 2016).

[11] R. J. Finno, F. T. Voss, E. Rossow, and J. T. Blackburn, "Evaluating damage potential in buildings affected by excavations," J. Geotech. Geoenviron. Eng., 1199-1210, 2005.

[12] M. Son, and E. Cording, "Responses of buildings with different structural types to excavation-induced ground settlements," J. Geotech. Geoenviron. Eng., 323-333, 2011.

[13] L. Bryson, and M. Kotheimer "Cracking in walls of a building adjacent to a deep excavation,” J. Perform. Constr. Facil., 491-503, 2011.

[14] M. Boscardin, and E. Cording "Building response to excavation-induced settlement," J. Geotech. Eng., 115:1(1), 1-21, 1989.

[15] Inclinometer measurement, http://www.zeminarastirma.com/deneyler /inklinometre_deneyi_nedir_nasil_yapilir.html (Accessed on September 2016).

[16] A. Erken, T. Öztürk, and Y. Mahmutoğlu "Soil investigation report," Istanbul Technical University, Decision no. 198 dated 23.06.2008 (in Turkish).

[17] TS 498, "The loads and loading cases due to use and occupancy in residential and public buildings," Turkish Standards Institute, Ankara, Turkey, 1997.

[18] Turkish Earthquake Regulation, "Specification for buildings to be built in earthquake regions," Ministry of public works and settlement, Government of the Republic of Turkey, 2007.

[19] TS 500, "Requirements for design and construction of reinforced concrete structures," Turkish Standards Institute, Ankara, Turkey, 2001.

[20] A. M. Gözübol, and F. A. Yüksel "Investigation reports of geophysical and geological," Istanbul University, April 24, 2008. (in Turkish).

[21] A. Erken, "Geotechnical report", 2007-2008, Istanbul Technical University, Istanbul (in Turkish).

[22] T. Cosgun, H. Yıldırım, İ. Öztaş, M. Özdemir "Expert reports: Nos. 2008/50E and 2009/252E”, Istanbul, September 24, 2012.

About Authors:

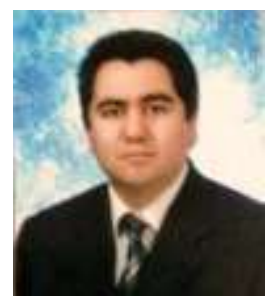

Turgay Cosgun, Assistant Professor, is currently employed by Department of Civil Engineering at Istanbul University. Dr. Cosgun graduated from Akdeniz University with BS, and from Istanbul University with MS and PhD in Department of Civil Engineering. During his graduate education, he worked as a Research Assistant in the Department of Civil Engineering at Istanbul University in between 1993 and 2004. His research areas are structural engineering, nonlinear analysis, failure loads and second-order theory.

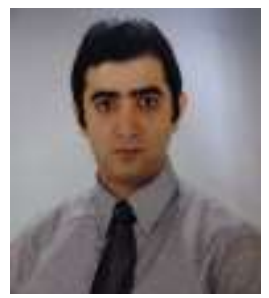

Baris Sayin, Assistant Professor, is currently employed by Department of Civil Engineering at Istanbul University as a academician. Dr. Sayin graduated from Istanbul University with $\mathrm{BS}$, MS and $\mathrm{PhD}$ in Civil Engineering. During the graduate education, he worked as a Research Assistant in the Department of Civil Engineering at the University in between 2000 and 2009. Dr. Sayin collaborated with Prof. Dr. Hamid Saadatmanesh on CFRP in RC structures as a Visiting Scholar in the Department of Civil Engineering and Engineering Mechanics at The University of Arizona for 12-months from September 2012. His research areas are fiber composites, industrial wastes and RC structures. He has authored more than 60 papers for journals and scientific events.

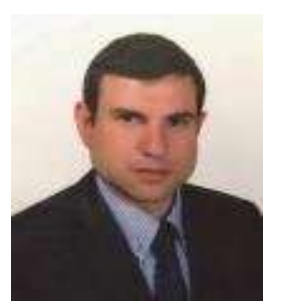

and RC-structures.

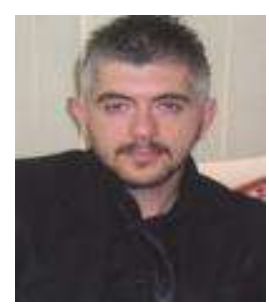
aided design, computer programming in civil
engineering, blasting effects, strengthening techniques of structures. He
has collaborated actively with researchers in several other disciplines of has collaborated actively with researchers in several other disciplines of mining and architectural science.
Cemil Akcay, Assistant Professor, is currently employed by Department of Civil Engineering at Istanbul University as a Civil Engineer. Dr. Akcay graduated from Istanbul University with $\mathrm{BS}$, MS and $\mathrm{PhD}$ in Civil Engineering. During the graduate education, he worked as a civil engineer at Department of Construction and Technical Affairs, Istanbul University in between 2005 and 2015. His research areas consist of engineering management, historical-

Baris Yildizlar is a Assistant Professor in the Department of Civil Engineering at the Istanbul University where he has been a faculty member since 2001 . He completed his $\mathrm{PhD}$ at Istanbul University and his undergraduate studies at the University. His research interests earthquake engineering, existing structures, dynamic analysis, RC structures, finite elements method, computer structures, finite elements method, computer 